\title{
Optimization of energy storage and system flexibility in the context of the energy transition: Germany's power grid as a case study
}

\author{
Leonardo K. K. Maia* and Edwin Zondervan
}

\begin{abstract}
In this work we explore the ramifications of incoming changes brought by the energy transition, most notably the increased penetration of variable renewable energy (VRE) and phase-out of nuclear and other conventional electricity sources. The power grid will require additional flexibility capabilities to accommodate such changes, as the mismatch between generation and demand is bound to increase. Through mathematical modeling and optimization, we simulate the German power grid and investigate the requirements of on-grid large-scale storage. Different scenarios are evaluated up to 2050 , when $80 \%$ of the gross electricity consumption is planned to be provided by renewable energy. Dispatchable power plants will play a key role in the transition to an energy mix with high shares of VRE. Around $120 \mathrm{GW}$ of additional large-scale storage are required until 2050. Between the electrochemical technologies evaluated, lithium-ion was the best candidate. A strong reliance on dispatchables was observed, in case the commissioning of VRE plants goes slower than planned. Energy curtailment increases with VRE shares, with up to 14 TWh curtailed in high VRE scenarios in 2050.
\end{abstract}

Keywords: Energy systems modeling, Optimization, Germany power grid, Energy storage, System flexibility, Energy transition

\section{Introduction}

The electricity sector is undergoing fundamental changes around the globe in its structure and paradigms following the shift to cleaner energy mixes. International pressure shaping new policies, renewable energy costs plummeting and growing public interest on climate change, to cite a few, are interdependent factors that drive these changes forward. In Germany, these changes are steered by the Energiewende, or Energy Transition: a collection of targets set by the federal government for greenhouse gas emission reductions (80-95\% reduction relative to 1990), increase of renewable energy share on gross electricity consumption ( $80 \%$ by 2050 ) and additional targets regarding the heat and transport sector. Nuclear energy

\footnotetext{
* Correspondence: leonardo.maia@uni-bremen.de

University of Bremen, Leobener Str. 6, 28359 Bremen, Germany
}

phase-out will also put pressure on the increase of electricity generation from renewables, creating a gap of over $70 \mathrm{TWh}$ of yearly electricity generationrepresenting around $12 \%$ of the gross electricity generation in 2017 [1] - when the last plants are switched off by 2022 [2].

Wind and photovoltaic generation face the additional challenge of being a variable source of electricity (commonly referred to as variable renewable energy, VRE), requiring tools and strategies from the power grid to deal with the resulting mismatch between generation and demand. Dispatchable generation (natural gas, pumped hydro plants), improvements in grid efficiency to remove bottlenecks and demand-side management all come at play to mitigate the effects of fluctuating electricity generation, but another powerful tool is gaining more and more ground as far as future power grids are concerned: energy storage (ES). Large-scale energy storage will

(c) The Author(s). 2019 Open Access This article is distributed under the terms of the Creative Commons Attribution 4.0 International License (http://creativecommons.org/licenses/by/4.0/), which permits unrestricted use, distribution, and 
play an important role in future energy mixes with high penetration of VRE [3, 4]. Several energy storage technologies are available in the market with a wide range of power ratings, storage capacities, response times, efficiencies, capital costs, scalability and so forth. Therefore, to sort out the most suitable candidates, a thorough analysis involving economical, technical and environmental aspects is needed.

Numerous studies analyze the potential candidates for energy storage in future grids within these three aspects. Gallo et al. [4] perform a review of energy storage technologies on the transition context, stating that economic feasibility of ES and establishment of well-suited regulations are major issues slowing down ES deployment. Gimeno-Gutiérrez et al. [5] analyze the potential for expanding PHS capacity in Europe, heavily constrained by populated areas, protected natural areas and transport infrastructure. According to their methodology, Germany could still expand their PHS capacities in 8 to $14 \mathrm{GWh}$. Buttler and Spliethoff [6] present the current state of water electrolysis as an option for energy storage (power-to-gas). Further projects are required to strengthen business cases, as well as optimization of the dynamic operation of the electrolysis systems. Pleßmann et al. [7] present a dynamic simulation for a $100 \%$ renewable energy global scenario. To guarantee matching of load demand, primary energy sources are coupled with battery energy storage, thermal storage and power-to-gas technologies. In their model, power-to-gas and thermal storage play a critical role in balancing the VRE generation profiles. Palizban and Kauhaniemi [8] present a matrix with the available energy storage technologies and their applications in grid services. They argue that an optimum ES technology selection would consider multiple options to match all the required grid needs, such as spinning reserve, power quality, black start, voltage support, etc. Their work focus on a technical point of view rather than an economical one. Schlachtberger et al. [9] show results for an optimization model of the European power grid to study the implications of the $\mathrm{CO}_{2}$ emission reduction targets. Regarding energy storage, their results favor a combination of solar generation and daily battery ES to balance the variations of wind generation over several days. Brivio et al. [10] evaluates battery energy storage systems for primary frequency control in a case study of Italy. A $1 \mathrm{MW} / 1 \mathrm{MWh}$ system is simulated in MATLAB where two operation modes are investigated through fuzzy logic controllers. Jülch [11] presents a comparison between ES options using a levelized cost of storage methodology, where PHS, CAES and batteries are mentioned as candidates for short-term ES, with batteries expected to have a sharp decrease in costs in the near future. Other indeveloping technologies are also starting to get traction, but still need further improvement and pilot projects, such as ocean renewable energy storage (ORES) [12], where the concept is storing energy deep underwater in concrete spheres. To store energy, water is pumped out of the spheres, and allowed to flow back in through a turbine to generate electricity when needed.

Pumped hydro storage is by far the most used ES technology on the globe, with the most competitive capital and operation costs. The challenge for PHS are the geographical limitations and the opposition for installing new storage units. Germany-the focus of this manuscript-is not expected to expand its PHS capacities significantly in the next decades, due to already having a highly developed and saturated hydropower market [13]. CAES is also currently a competitive storage option, but new plants are also geographically constrained, along with relatively low roundtrip efficiency for large-scale storage. Electrochemical ES at the grid-level offers flexibility, high roundtrip efficiency and can provide several ancillary services. Their relatively high capital costs, especially in the case of lithium-ion batteries, are expected to drop in the coming decades as indicated by the literature. A combination between the existing capacity from PHS and CAES, and newly installed electrochemical ES plants is likely to be the scenario for the future grid.

The final requirement for large-scale energy storage in a given power grid will also depend on the development of demand-side management, flexible combined heat and power, power-to heat, removing bottlenecks from the current transmission grid, the availability of dispatchable power generation [14], and a well-established transmission network that interconnects neighboring countries. Changes in the transport sector are also expected to play a crucial role in re-shaping the energy sector. Hybrid plug-in electric cars and compressed natural gas cars will likely serve as the stepping stones to an electric vehicle-dominated future [15], consequently increasing the electricity share to the transport sector, but also potentially providing additional storage capacity with the increase of the electric vehicle fleet. All of the aforementioned items contribute to the overall ability the grid has to accommodate fluctuations from VRE generation or, in other words, they increase the system flexibility.

The Roadmap Speicher [14] - a report published by the Fraunhofer Institute on the challenges of energy storage implementation within the scope of energy transition in Germany-draws a few noteworthy conclusions: 
- no immediate energy storage requirements: in the medium-term, the power grid is still capable of handling VRE generation;

- the importance of system flexibility tools to be implemented associated to newly commissioned VRE plants;

- relevancy of seasonal storage in 90\% VRE scenarios: long-term storage becomes important in very high VRE penetration mixes;

- batteries for primary control reserve, due to their fast response times and high efficiencies;

- cost reduction of storage technologies as being a critical factor for their competitiveness.

Therefore, even though large-scale energy storage is not an urgent requirement, given the current rate new VRE plants are commissioned, estimating the required capacities in future grid scenarios will help shape government policies and steer investments in the right direction. Moreover, grid-connected battery systems will aid the accommodation of large shares of VRE.

Energy systems modeling and optimization provides invaluable information regarding future energy mixes, and it has been gaining considerable traction in research in the last years, with over 115,783 search hits in 2015, 123,675 in 2016 and 144,000 in 2017, for the keyword "energy systems modeling" in Science Direct [16].

Cebulla et al. [17] present an energy system model that spans across Europe and addresses system flexibility through storage and dispatch. Electrical energy storage requirements range were estimate between 126 and 272 GW for Europe by 2050, assuming a renewable share of $89 \%$. The authors emphasize on the investigation of an optimum spatial distribution for storage expansion, as well as storage dispatch. Pleßmann and Blechinger [18] also present an optimization model that covers Europe, dividing it into 18 country groups, where an optimal transition pathway to the 2050 Energy Transition targets is investigated. An increase in the levelized cost of electricity (LCOE) from 6,7 to 9,0 ctEUR/kWh is calculated, with required investments of 403 billion EUR in the power grid. Regarding energy storage capacities, 432 GW of storage is estimated by 2050. A comparison with the results of Cebulla et al. and Pleßmann and Blechinger concerning energy storage requirements are presented in Section 3.

Pfenninger et al. [19] perform a review on energy systems optimization models, motivated by the rise of more restrictive climate policies in the last decades. Four modeling challenges are listed: resolving time and space, balancing uncertainty and transparency, addressing the growing complexity, integrating human behavior and social risks and opportunities. The authors advise to carefully consider whether well-established methods are suitable for the coming challenges of energy systems, and emphasize the role of smaller, more nimble models to solve specific questions rather than large integrated models. Schill et al. [20] present an open-source model to investigate the role of power storage in systems with high shares of VRE. A sensitivity analysis is performed on long-run parameters due to their increased uncertainty, such as biomass availability, PV costs, weather and wind offshore availability. Results show that storage requirements grow substantially at $80-100 \%$ of renewables and is even more relevant if other sources of flexibility are limited. Lunz et al. [21] perform a systematic scenario analysis for 2050 in Germany, allowing a wide-range of VRE shares and demand throughout the scenarios. Residual load curves are used as input data to the model. Babrowski et al. [22] also focus on the German power grid, evaluating electricity ES requirements until 2040 through an energy systems model. The authors find that ES, gas turbines and load shift potential are the main sources of system flexibility for the coming grid changes in 15 to 20 years. In Gils et al. [23], a network model for Europe is developed, with short- and long term storage and concentrated solar power as dispatchable backup, with hourly resolution for dispatch of power generation, storage and transmission. Usage of storage and concentrated solar power can keep curtailments below $20 \%$ of the demand for VRE shares of up to $100 \%$. Thus, important takeaways from recent literature on energy systems modelling and the knowledge gaps identified are listed below.

- Several energy system models in the literature take into account energy storage. However, some approaches are oversimplified by implementing a generic battery system, or missing certain technical aspects of the technology (e.g., selfdischarge). A comprehensible evaluation of electrochemical storage technologies, taking into account different technologies, their costs, capabilities and limitations within an optimization framework is lacking.

- The role of system flexibility in the final requirements for large-scale short- and long-term energy storage. This includes dispatchable power plants, electrification of the transport sector, electricity trade within the European grid, energy curtailment, etc.;

- Importance of scenario analysis due to uncertainty of future installed capacities, demand, prices, etc. 
The novelty of this work is motivated by the lack of a comprehensible optimization model in the literature that considers simultaneously: 1) several system flexibility options available, such as dispatchable generation, storage, electricity trade and curtailment; 2) evaluation of electrochemical energy storage technologies, taking into account all relevant operation-related parameters, such as self-discharge, roundtrip efficiency, energy-to-power ratio, as well as a careful calculation of their annualized life cycle costs; 3) a scenario-based evaluation, taking into account the rate of energy transition to a renewable-heavy energy mix; 4) Time series for load and generation with hourly temporal resolution. Therefore, we present a linear programming (LP) model of the German power grid, covering two possible corridors as scenarios for 2025, 2035 and 2050. The first corridor depicts the successful achievement of the energy transition plans for 2050 where, among other goals, is having $80 \%$ of the gross electricity consumption from renewables, and $80-95 \%$ of greenhouse gas reductions (relative to 1990). The second one lags behind in renewable energy commissioning and phasing-out of conventional generation. Every year (scenario) in each corridor has a distinct dataset for installed capacity, generation, demand, dispatch and import/export capabilities and costs. A detailed description of each scenario is given in Section 5.1.4. Three candidates for electrochemical energy storage are evaluated: lithium-ion, vanadium redox flow and sodium-sulphur batteries. Their annualized life cycle costs (ALCC) and technical parameters are all included and the most suitable technology is endogenously selected, meaning that it is a decision variable within the model. The model also includes exogenous (data input) demand and electricity generation (renewables and baseload), with endogenous dispatchable generation, import and exports, storage scheduling and capacity estimation.

\section{Results and discussion}

Simulations for the proposed scenarios will provide insight with respect to system flexibility, storage requirements, the impact of VREs, electricity market (imports and exports) and dispatchable generation. The shift from a baseload-heavy to a variable-heavy mix puts to test how flexible the grid can be at accommodating such changes within the boundaries defined in the model.

\section{Energy mix, dispatchable generation}

Figure 1 depicts the generation from dispatchable sources across all evaluated scenarios. The energy generation from dispatchables increases around $36-50 \%$ from 2016 to 2025 for both corridors, to fill the gap from nuclear energy phase-out. Until 2035, Corridor B requires $\sim 28 \%$ more electricity from dispatchables than in Corridor A due to a quicker phase-out of coal plants. Natural gas and synthetic natural gas play a role in providing enough electricity in 2050 with the expected increase in the EV fleet. With the faster commissioning of VRE sources in Corridor B, most of this additional demand can be covered by renewables, whereas in Corridor A not so much, thus the higher reliance (203 TWh vs. 189 TWh) on dispatchables than in Corridor B. Pumped hydro generation increases proportionally to the additional capacity installed in each scenario, and accounts for roughly $30 \%$ of dispatchable generation by 2050 in both scenarios. In Germany, hydro generation is not expected to increase at the same rate as other renewable sources due to geographical and topological limitations.

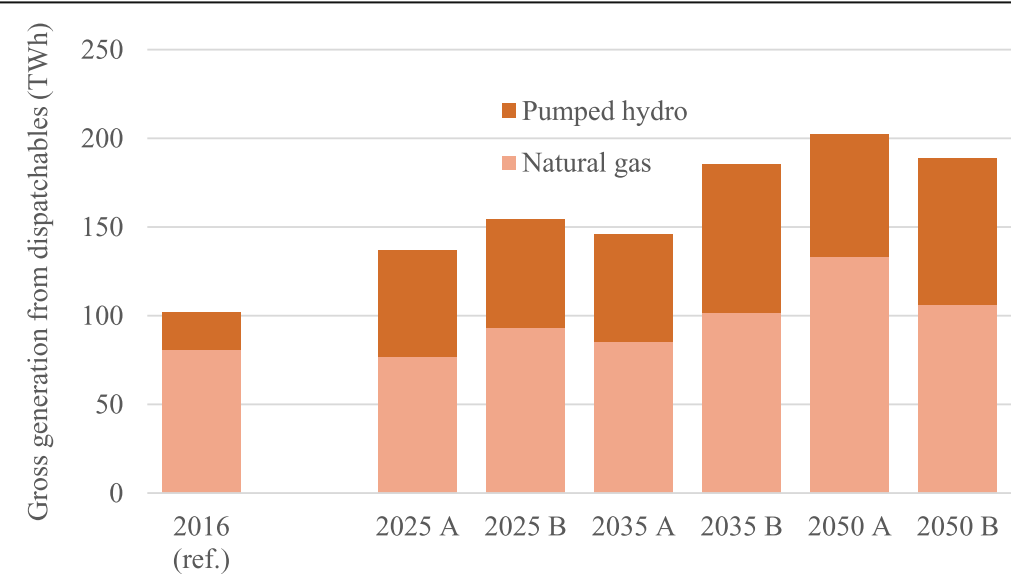

Fig. 1 Results for gross generation from dispatchable sources (natural gas and pumped hydro) across all scenarios. Values for 2016 correspond to real data for that year 


\section{Storage requirement}

The results for additional storage capacity show $50 \mathrm{MW}$ of Li-ion storage capacity on top of the existing $7 \mathrm{GW}$ of PHS for 2035B. For 2050B around $120 \mathrm{GW}$ of additional storage was calculated. In Corridor A, no additional storage capacity is required, meaning that the existing PHS capacity can provide enough storage to balance the higher shares of VRE. Clearly, storage requirements increase sharply with VRE penetration after a certain point. Scenario 2050 B has $64.8 \%$ of its gross generation from VRE sources, while 2050 A has $47.7 \%$. Figure 2 shows the scheduling of energy storage throughout the year for both scenarios. Long-term $(>1$ month) storage is covered by the existing PHS storage plants, while medium- and short-term storage is covered by the additional Li-ion storage.

The selected storage technology was lithium-ion. The two main reasons are the low ALCC of lithium-ion and its high roundtrip efficiency. Lithium-ion storage at 95\% roundtrip efficiency (against $80 \%$ for VRFB and $85 \%$ for Na-S) makes it extremely competitive due to how often short-term storage is cycled. If all batteries had the same roundtrip efficiency, the other two technologies only become attractive when the ALCC of lithium-ion is two or three times higher, due to its energy-to-power ratio (discharge time) of 2.

\section{Electricity market}

Imports and exports provide an immediate solution to surplus and deficit, effectively reducing the (more expensive) solution of grid storage. Figure 3 presents the import/export balance results for the simulations. The phase-out of nuclear plants starting from 2025 greatly affects the import/export balancing, significantly reducing exports compared to the reference case in 2016. In Corridor A, the balance shifts to negative, meaning

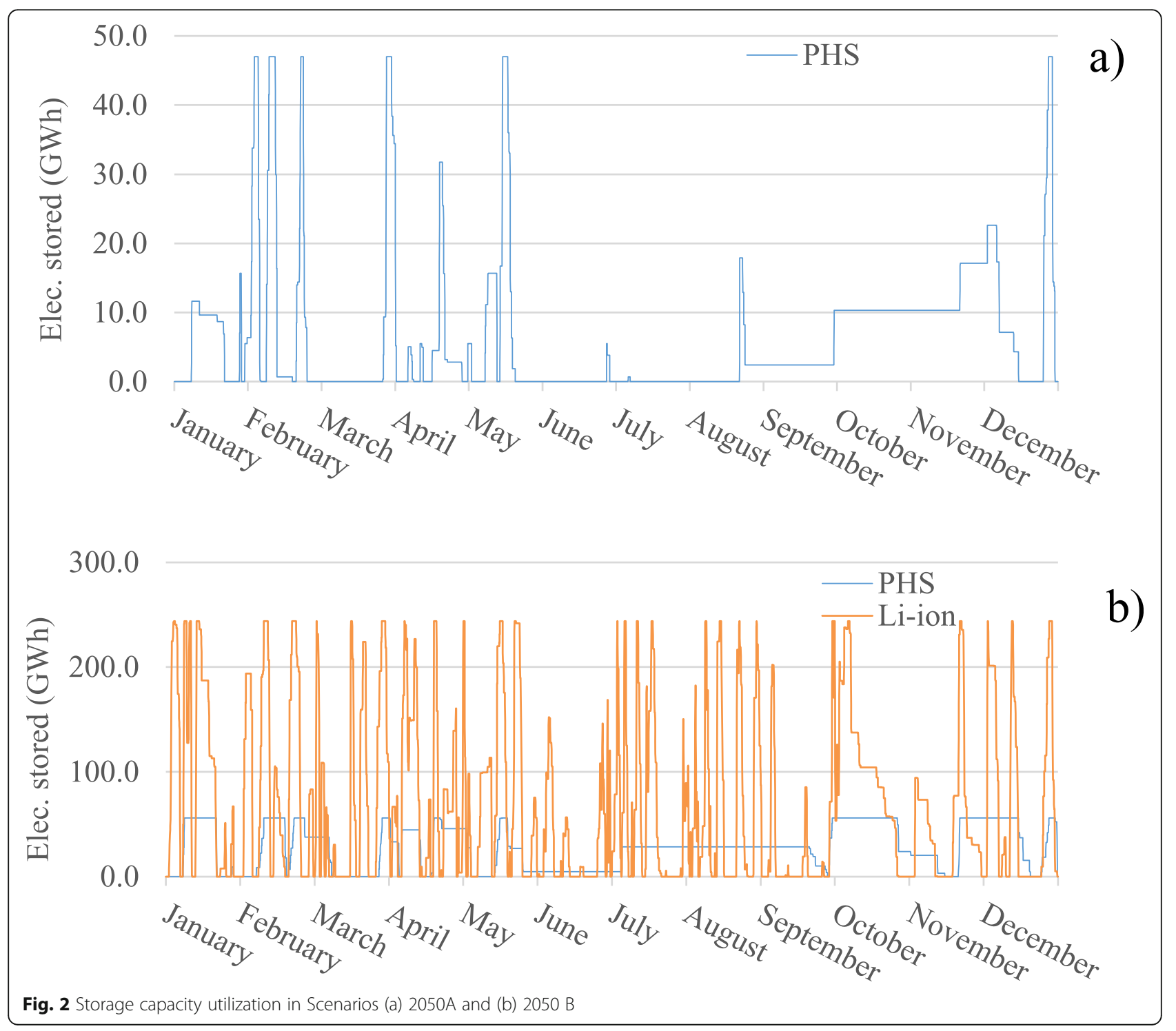




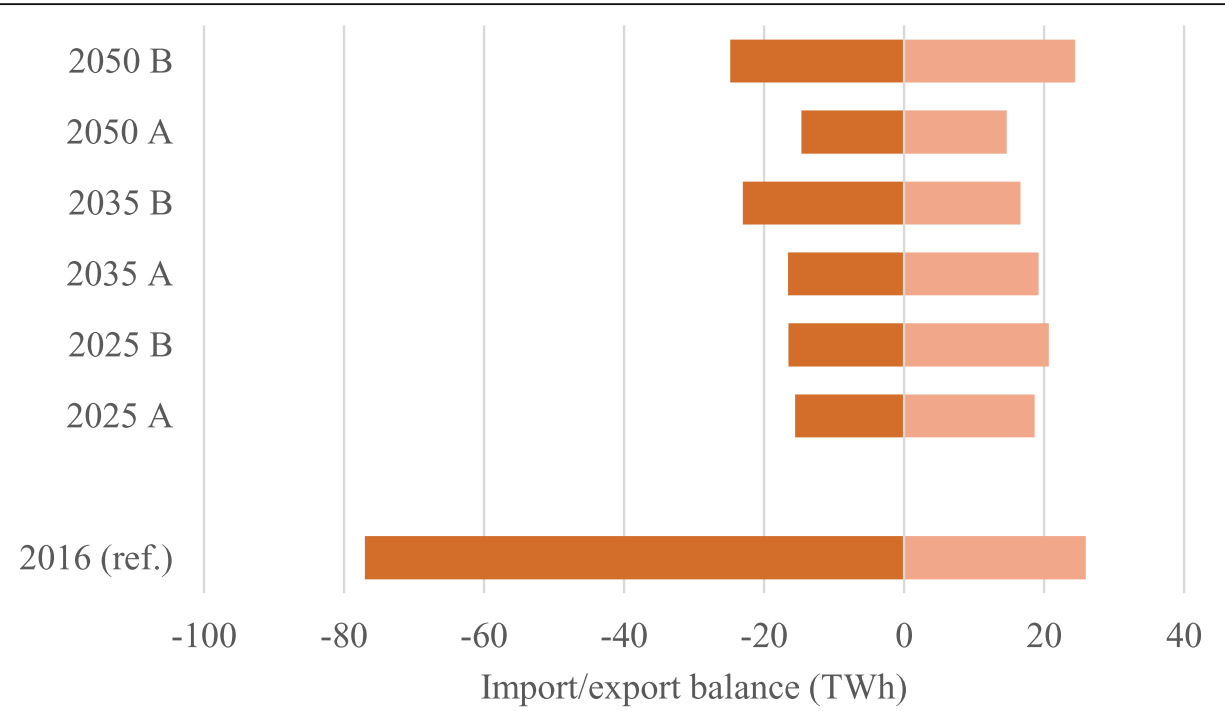

Fig. 3 Results for import/export balance (Negative: exports; Positive: imports). Values for 2016 correspond to real data for that year

imports exceed exports, in 2025A and 2035A. In 2050A, the balance is almost zero, as the difference between imports and exports is around $7 \mathrm{GWh}$. In Corridor B, with an increasing share of VRE from 2025 to 2050, surpluses and deficits hours are more frequent, leading to higher exports and imports.

The question here is whether, in future years, there will be enough available electricity to import from neighboring countries, as they will also be likely undergoing energy transitions of their own, making efforts to remove conventional generation from their energy mixes. Some works [21, 23] discuss about the importance of an integrated market in Europe, as it might help bring electricity costs down. Lunz et al. argue that VRE shares projections are often smaller in neighboring countries than in Germany, thus conventional plants would be able to sustain the imports.

It must be noted that here imports and exports have both an upper boundary for the total electricity traded in the years as well as one for hourly trades. The hourly values were estimated based on import/ exports data from 2016/2017 [1]. An important observation is that, if such hourly upper boundaries are relaxed, storage requirements are greatly affected. That is, if electricity can be theoretically traded without an upper limit at a certain time of surplus or deficit, that evidently provides enough flexibility so that storage becomes unnecessary. Figure 4 presents the yearly picture for imports/exports scheduling for 2050A and 2050B. The main takeaways here are: a) the larger volume of exports in $B$ due to the higher occurrence of surplus periods, expected in high VRE penetration mixes; and b) the seasonality of traded electricity, being noticeably more frequent during winter months, where PV generation is lower.

\section{Energy curtailment}

Electricity curtailment is a flexibility tool that can be used as an alternative to installing additional storage facilities. Curtailment is allowed in the model as way to deal with surplus electricity. Figure 5 shows the total electricity curtailed in each scenario. A correlation between VRE installed capacity (wind and PV) and electricity curtailment is also observed, indicating that curtailment increases with higher VRE capacities. This can be explained due to the increase in peak generation, leading to more frequent occurrences where generation exceeds demand, the electricity market is saturated and energy storage is already at full capacity.

Corridor B has substantially more electricity curtailed than A, reaching up to almost $14 \mathrm{TWh}$ in 2050. Even curtailed values from 2025B already surpass 2050A. In this case, curtailment is free, meaning that the model allows an unlimited amount of electricity to be curtailed, if deemed necessary for the optimal solution. In case curtailment is limited, being a possibility discussed in [24], storage requirements would likely be much higher. The most obvious and immediate action to deal with a surplus is exporting electricity, but exporting is limited by both yearly totals and hourly upper bounds. Thus, after reaching those upper bounds, the second-best course of action is to curtail, considering that enough storage capacity is already in place to satisfy the demand.

A possible solution to avoid energy curtailment in high VRE penetration scenarios is power-to-gas $[6,25]$. This 


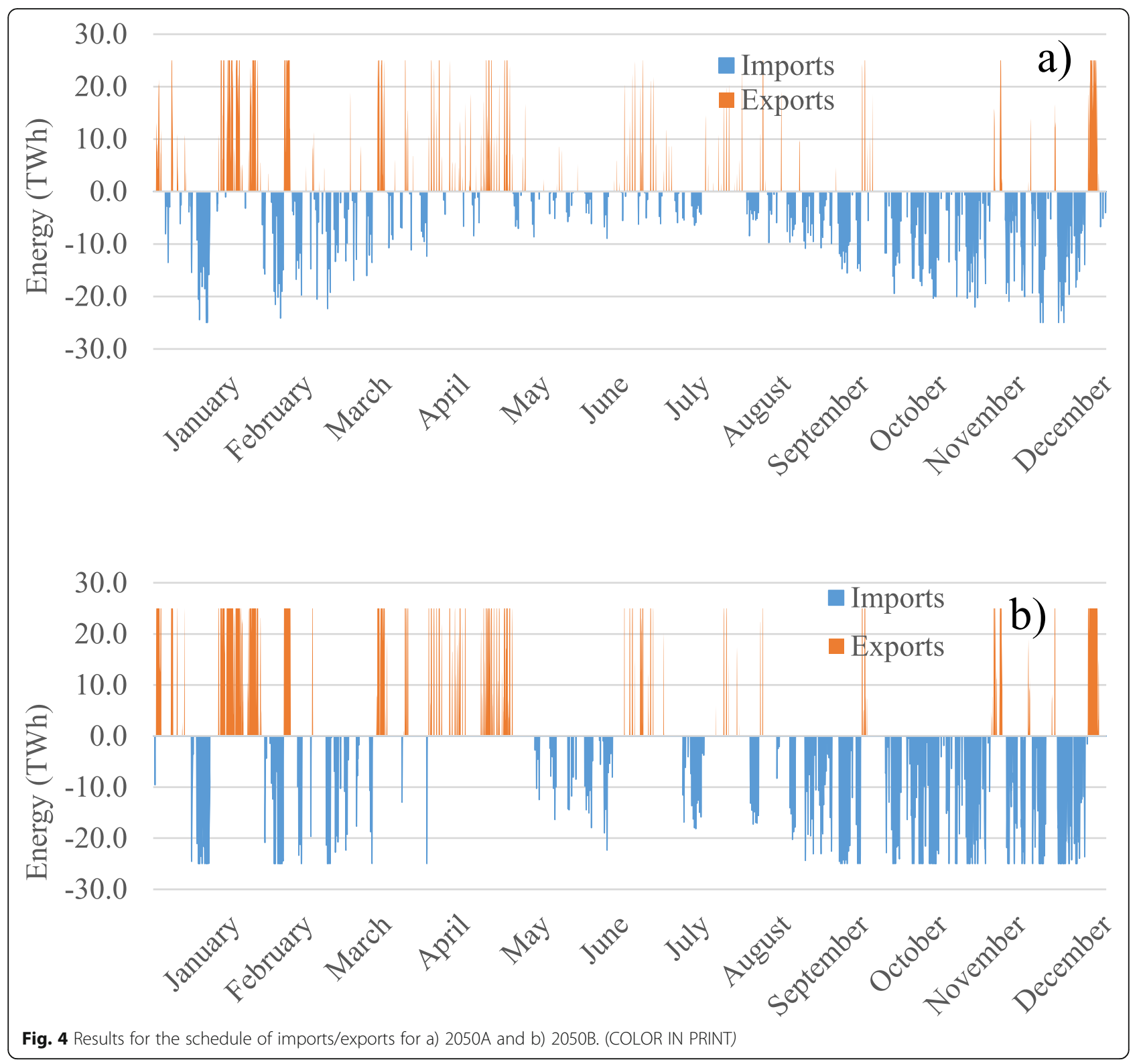

would allow an alternate storage option by means of storing the produced hydrogen, but more importantly, producing fuels through renewable energy allows a clean crossover to the heat and transport sector. Granted, investments in infrastructure are necessary to accommodate the transition, such as electrolysers and hydrogen storage tanks, but in first analysis it is an attractive option with respect to decarbonization and minimization of curtailment.

\section{Financial overview: revenue, costs}

An overview of the import-export balance, dispatchable generation costs and storage costs are presented here. Model results are given by Fig. 6. Since the objective function of the model is to maximize the "financial balance" composed by these costs and revenues, evidently the optimal result aims at maximizing exports (or endogenously installing storage capacity) and choosing the option that leads to the least costs between dispatchable generation, imports and storage capacity.

The import-export balance changes drastically when compared to the reference case in 2016, mainly due to lower exports, as discussed in the Electricity Market section. In Corridor A, the balance is negative by $€ 162, € 149$ and $50 €$ million in 2025A, 2035A and 2050A, respectively. In Corridor $\mathrm{B}$, the balance is only positive for $2035 \mathrm{~B}$, with $151 €$ 


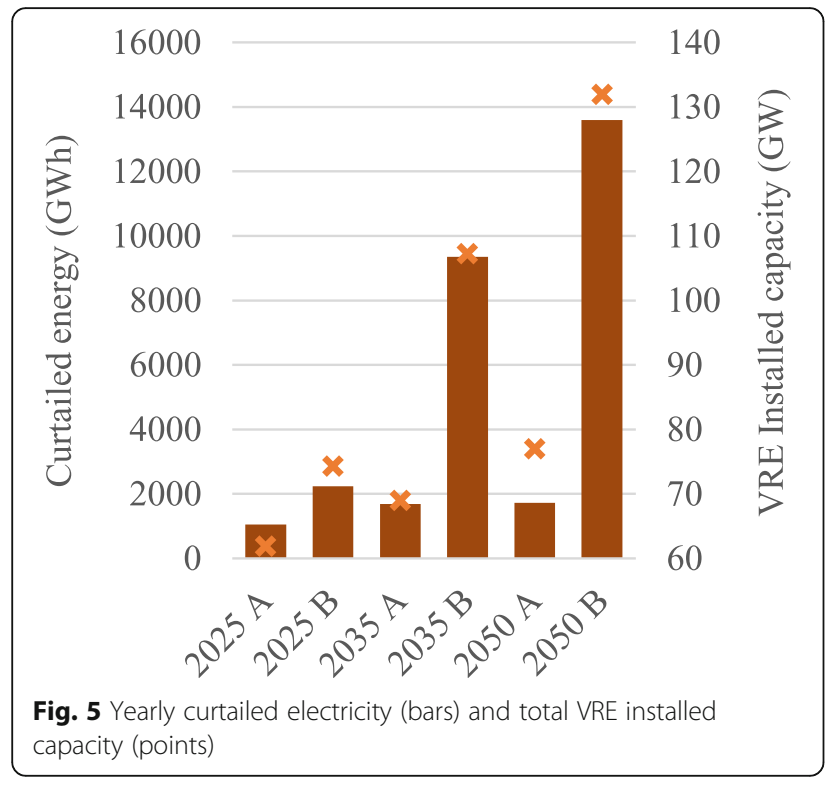

million. Negative balances of $203 €$ and $67 €$ million happen in 2025B and 2050B. Dispatchable generation costs are measured solely through natural gas purchases, as pumped hydro is assumed to have negligible marginal costs for producing electricity. Required investment in additional storage capacity (Li-ion) is of around $27 €$ million in $2035 \mathrm{~B}$ and $130 €$ billion in 2050B. 2050B is the scenario with the highest required storage $(120 \mathrm{GW})$, therefore requiring the highest annual investment. These values are annualized throughout the lifetime of the system. Several factors in the model affect the final required storage capacity: the upper bounds for imports/exports, available dispatchable generation, dataset assumptions for renewable energy, demand and installed capacities. The observation that follows here is that storage becomes critically relevant when VRE reaches $70-80 \%$ of gross electricity generation. The uncertainty around the aforementioned factors, however, should be evaluated further so that their contribution to the final required storage capacity can be properly quantified.

\section{Limitations}

A critical comparison of the results with other energy systems models in the literature $[14,17,20]$ show different estimations for the required energy storage capacity by 2050. In Pape et al. [14], the estimations are in line with the results in this model for the midterm (2035) energy storage expansion in Germany: 0 to $20 \mathrm{GW}$ of additional storage capacity, depending on the degree of flexibility of new consumers, such as electric vehicles, thermal heat pumps and air conditioning units. In this manuscript, an inflexible integration of electric vehicles was assumed, with no Vehicle-to-Grid capabilities. In Pleßmann and Blechinger and Cebulla et al. [17, 18], where models for the European network are presented, the estimations are lower, with $432 \mathrm{GW}$ (but only $22 \mathrm{GW}$ coming from batteries, whereas the majority comes from power-to-gas plants) and 126-272 GW, respectively. In both cases, power-to-gas dominates the storage capacity expansion, consolidated as a competitive long-term storage option mostly due to an assumed CAPEX reduction of one-third between 2016 and 2050 for PtG [18]. The focus given to electrochemical energy storages in this initial version of the energy system model was also due to the intention of a future integration with a lower-level optimization model

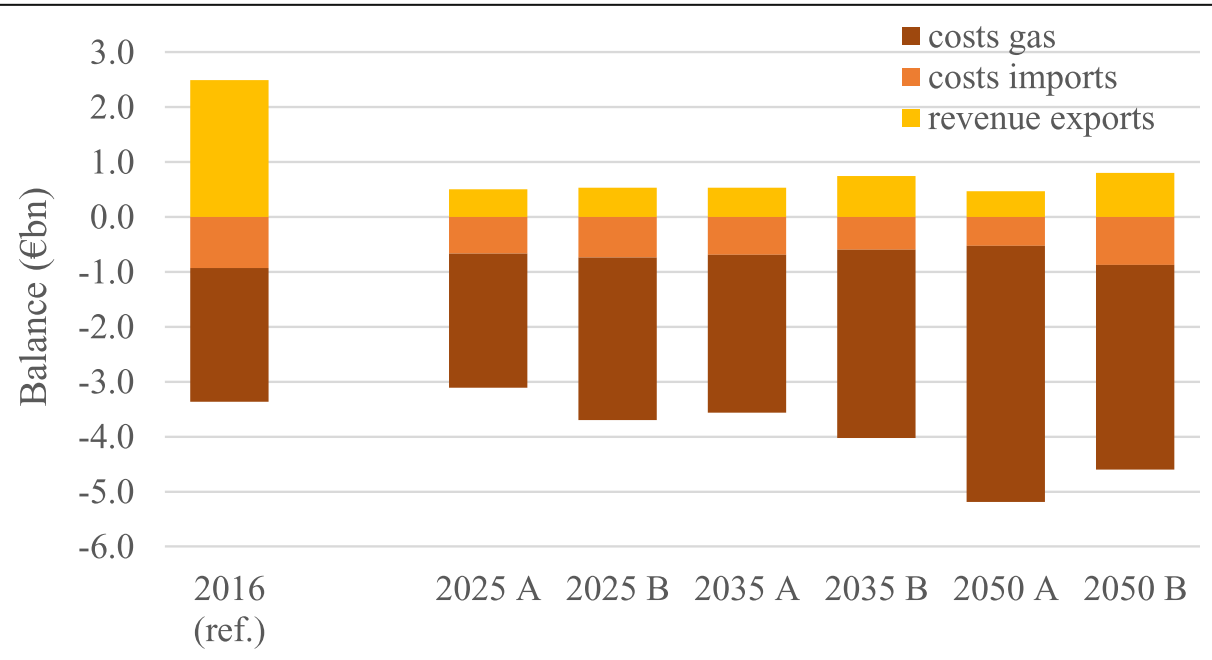

Fig. 6 a) Financial overview of the annual balance of the grid. (COLOR IN PRINT) 
of battery energy storage systems developed by the authors and already published [26]. In this approach, optimal charge-discharge strategies are investigated, aimed at maximizing battery lifetime, which ultimately impacts the economic feasibility of such systems.

Another aspect of the model that can skew the results towards an underestimation of storage demand is that the power grid in Germany is not explicitly modeled. Transmission and distribution capabilities are simplified through a "copper plate" approach at this stage of the model. Transmission bottlenecks and losses in distribution would further increase energy storage requirements. The lack of greater detail of the European electricity sector also impacts the results by potentially underestimating the benefits of integrated energy supply and overestimating the flexibility potential provided by Germany's neighbors.

The uncertainty for some of the model assumptions also affects the final storage capacity required. Allowing higher upper bounds for imports-exports, or to assume higher available dispatchable generation may reduce required storage capacities. Demand projection is also a source of uncertainty, as it is challenging to predict how fast the transportation sector will shift to electric vehicles. Additionally, the objective function (grid gross profit) is rather sensitive to demand variations.

\section{Conclusions}

The proposed model allowed the evaluation of several facets of the German power grid in the context of the Energy Transition, where VRE shares are expected to grow considerably in the coming decades. Two timelines from 2017 to 2050 were evaluated, here called Corridors: Corridor A refers to a business-as-usual timeline, where the efforts to mitigate GHG emissions and commission renewable energy do not go as quick as expected; and Corridor B, where the goals are successfully reached. Results showed that dispatchable generation will play an important role in providing electricity ondemand in the short- and mid-term, even in the scenarios evaluated in 2050. Corridor A showed an even higher reliance in dispatchables due to the slower commissioning of VRE plants. Calculated storage expansion holds a strong correlation with VRE shares, with $50 \mathrm{MW}$ of additional storage implemented in scenario $2035 \mathrm{~B}$ and $120 \mathrm{GW}$ in scenario 2050B under the assumptions made. The most suitable electrochemical storage technology is lithium-ion, where its high roundtrip efficiency (95\%) provided a considerable edge over VRFB and NaS. The import-export balance changed significantly due to less available electricity for imports, caused by the phase-out of conventional sources. Corridor A presented negative balance (more imports than exports) in all years evaluated. Corridor B only had a positive balance in 2035 . The overall volume of electricity traded was significantly larger in Corridor B, due to higher shares of VRE that contribute to more frequent surplus and deficit hours along the year. Energy curtailment is also strongly correlated to VRE shares, where surplus periods are more frequent. Almost to $14 \mathrm{TWh}$ of electricity is curtailed by 2050B. Possible measures to reduce curtailment and storage demand are a further integration of the European power grid to allow for more electricity exchange, demand side management and flexible power-to-gas/-heat technologies as a way to integrate renewable energies into the heating and transport sector. Results also revealed a shift from positive to negative importexport balance in Germany, following the phase-out of baseload generation (nuclear and coal) and the increase in VRE. Investment to install the calculated storage capacity in 2050B would be considerably high, at around $€ 130$ billion of annual investments.

\section{Methods/experimental}

The mathematical model presented in this work can be used for establishing an optimal schedule of the electricity flow through the grid, estimating storage requirements (capacity and investments), and provides an overview of how the coming changes in the energy mix will affect the energy landscape. The electricity flow is optimized to minimize the investments costs of storage units, the costs of importing electricity and the operation of dispatchable plants, as long as electricity demand is satisfied. A time resolution of 1 hour is used, with a one-year time horizon, resulting in 8760 time steps. Such resolution proved to be a reasonable compromise between model accuracy and solving times. Moreover, most time series available in databases, such as demand and VRE profiles, have a temporal resolution of 1 hour [27, 28].

The mathematical model described in this manuscript is implemented in AIMMS (Advanced Interactive Multidimensional Modeling System)-a third-party software platform for optimization-based applications, used by companies such as Shell and Heineken [29]. AIMMS supports the implementation of several mathematical optimization problem types, such as linear programming, quadratic programming, nonlinear programming, mixed-integer programming, etc. The mathematical model in 
question is formulated as a linear program (LP), consists of 192.822 constraints and 113.884 variables, and is solved with the CPLEX solver, version 12.6.2.

In the following subsections, all assumptions, simplifications, data collection, scenarios, model elements included (and omitted) and model structure are described in detail.

\section{Model description}

Germany's power grid is modelled by assuming a bottleneck-free network extension throughout the country. Exchange of electricity within neighboring countries is allowed, both in and out (imports and exports). Electricity generation is not considered at a plant level, but aggregated throughout the entire country. The model contains two domains, as specified in Table 1: time $(\mathrm{t})$ and storage technologies (s). The domain of each parameter and variable is shown by subscripts with the respective domain indices.

\section{Model elements, assumptions and data collection}

Figure 7 shows the input data, model details and output data. Exogenous model parameters are presented in Table 2. The variables calculated by the model (endogenous) are presented in Table 3. Here we summarize how the data was gathered and processed prior to being used in the model:

- Demand: Hourly load time series for Germany were obtained from the European Network of Transmission System Operators for Electricity (ENTSO-E) [30]. This data represents gross consumption of electricity in Germany in the period. For the demand in future scenarios, the values were based on the NEP reports [31], where future consumption behavior is estimated taking into account energy efficiency measures, electromobility and the replacement of primary energy sources.

- Variable renewable energy: Hourly generation time series from wind and solar energy were obtained from the Netztransparenz platform [28], where data from all four TSOs in Germany $(50 \mathrm{~Hz}$, Amprion, TenneT and TransnetBW) is available. Since this data is only from a representative number of power plants, it is multiplied by a factor to match the total generation for the entire year. Onshore and offshore generation are aggregated.

- Baseload energy: Electricity sources that either operate in a baseload fashion (nuclear, coal) are aggregated in the same parameter, baseloadEnergy, so that the entire time horizon of the model has the same baseload generation, for each scenario. Biomass was also included in this category due to lack of hourly data. Biomass generation includes: solid and liquid biogenic substances, biogas, sewage gas, dump gas and the biogenic share of waste. All data for baseload energy was gathered from [1].

- Energy storage: Existing PHS capacity in Germany is considered in the model. According to the International Hydropower Association [13], Germany has around $7 \mathrm{GW}$ of installed pumped hydro power capacity in 2017, which accounts to roughly $40 \mathrm{GWh}$ of energy capacity.

- Dispatchable generation: Natural gas and pumped hydro generation are included in this category. Biogas is aggregated in the biomass baseload production. Synthetic natural gas (SNG) systems, nor Power-to-gas are explicitly modelled, but its impact is taken into account in the projections for natural gas generation, especially in the optimistic scenario. Hydrogen produced through power-to-gas technology is expected to be an attractive use for excess electricity. Part of this clean hydrogen will likely be used to produce SNG or even be consumed directly in gas turbines $[32,33]$. Two exogenous parameters describe their upper bounds (gasPeak and pumpedHydroPeak). The peaks are based on real data for the period [1]. A minimum (base) generation for natural gas is also specified (gasMinimum), representing the standby plant generation. Dispatchable generation in the model is endogenously calculated. No ramp-up/down constraints are considered as a simplification. Natural gas prices for the projected scenarios are taken from the NEP 2015 report [31].

- Imports and exports: Calculated endogenously, limited by lower and upper boundaries for both total yearly electricity traded and an hourly limit $[1,31]$. Recipients and sources of the electricity traded are

Table 1 Domains and indices in the model

\begin{tabular}{lll}
\hline Domains and indices & Description of domain & Units, elements \\
\hline$t \quad$ Time & Contains the temporal resolution and time horizon & Hours \\
$s \quad$ StorageTech & Contains the energy storage technologies considered & Lithium-ion, VRFB, Na-S, PHS \\
\hline
\end{tabular}




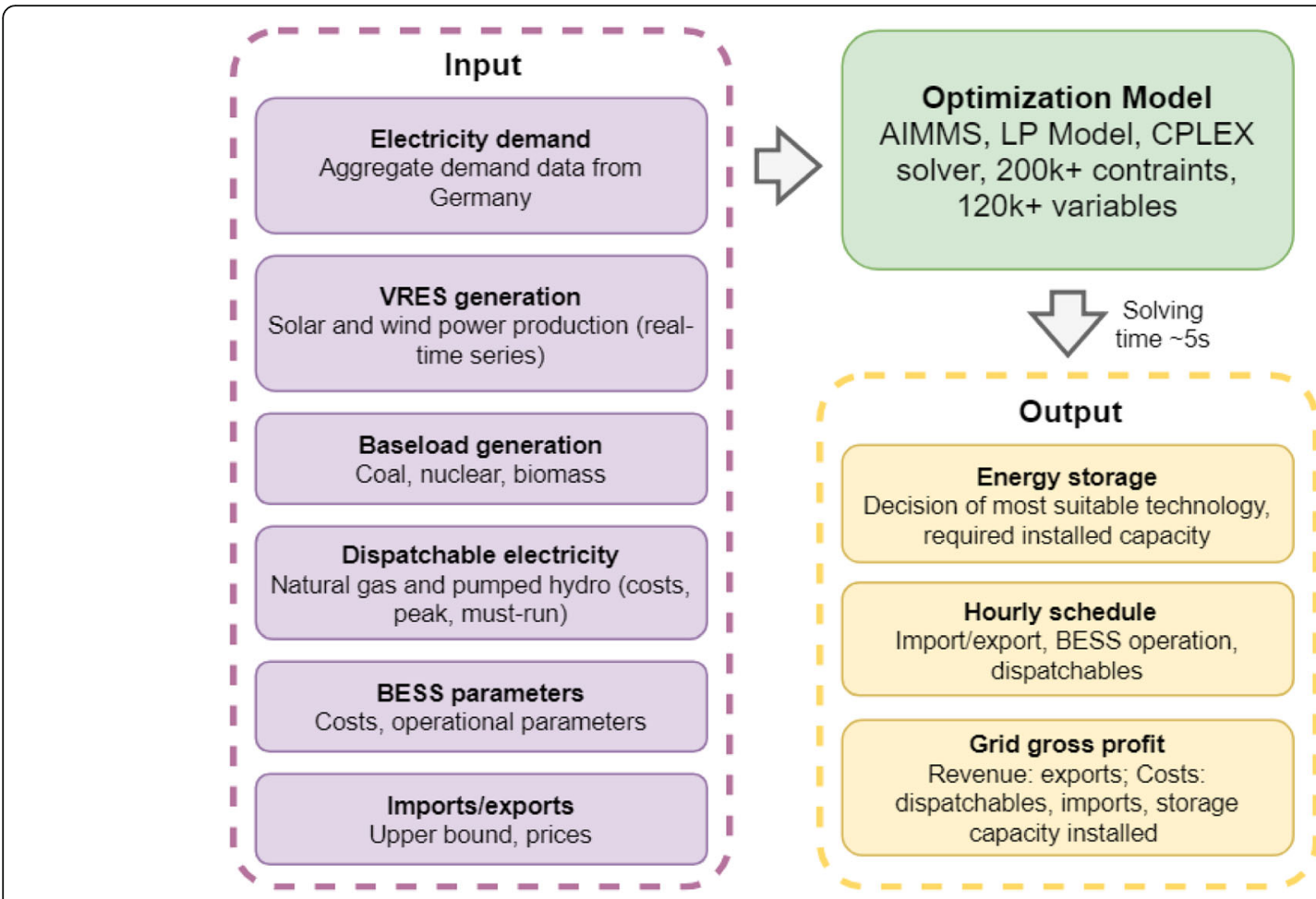

Fig. 7 Optimization model structure with input and output data

not specified. The flow of electricity is only accounted for in terms of inflows or outflows.

The following variables are calculated by the model (Table 3): total stored electricity at any given time
(storageCurrent $t_{t, s}$ ), installed storage capacity (storageCapacity $_{s}$ ), in- and outflows of electricity in the storage units $\left(\right.$ storeIn $_{t, s}$ and storeOut $\left._{t, s}\right)$, hourly dispatch of pumped hydro and natural gas (pumpedHydro ${ }_{t}$ and gas $_{t}$ ), imported and exported electricity (importElec $c_{t}$ and exportElec $c_{t}$ ).

Table 2 Parameters (exogenous) used in the model

\begin{tabular}{|c|c|c|}
\hline Parameters (exog.) & Description & Units \\
\hline demand $_{t}$ & Hourly demand & GW \\
\hline renewableEnergyt & Hourly total renewable generation (wind+PV) & GW \\
\hline baseloadEnergy $t_{t}$ & Hourly baseload generation (nuclear, coal, run-of-the-river, biomass) & GW \\
\hline gasPeak & Maximum peak production allowed for natural gas & GW \\
\hline gasMinimum & Minimum generation from natural gas at any given time & GW \\
\hline pumpedHydroPeak & Maximum peak production allowed for pumped hydro & GW \\
\hline costPerkWyr & Annualized costs for each storage technology & $€ / \mathrm{kW}-\mathrm{yr}$ \\
\hline enporatios & Energy-to-power ratio of storage technologies & - \\
\hline selfDischarge $_{5}$ & Self-discharge for each storage technology & - \\
\hline roundTripEffs & Roundtrip efficiency of each storage technology & - \\
\hline maxImport & Maximum total yearly imports & GWh \\
\hline MaxExport & Maximum total yearly exports & GWh \\
\hline maxImportHour & Maximum allowed hourly import & GW \\
\hline maxExportHour & Maximum allowed hourly export & GW \\
\hline priceExport & Cost of exporting electricity & $€ / G W h$ \\
\hline pricelmport & Cost of importing electricity & $€ / G W h$ \\
\hline priceGas & Cost of natural gas & $€ / G W h$ \\
\hline
\end{tabular}


Table 3 Variables (endogenous) calculated by the model

\begin{tabular}{lll}
\hline Variables (endog.) & Description & Units \\
storageCurrent $_{t, s}$ & Total stored electricity & GWh \\
storageCapacity $_{s}$ & Installed storage capacity & GWh \\
storeln $_{t, s}$ & $\begin{array}{l}\text { Flow of electricity from the } \\
\text { grid into storage units }\end{array}$ & GW \\
storeOut $_{t, s}$ & $\begin{array}{l}\text { Flow of electricity out of storage } \\
\text { units to the grid }\end{array}$ & GW \\
pumpedHydro $t$ & Hourly dispatch of pumped hydro & GW \\
gas $_{t}$ & generation & \\
importElec $_{t}$ & Hourly dispatch of electricity from & GW \\
exportElec $_{t}$ & natural gas & GW \\
\hline
\end{tabular}

\section{Electrochemical large-scale storage}

Three electrochemical technologies are selected for large-scale storage: vanadium redox flow batteries (VRFB), soldium-sulphur (Na-S) batteries and lithiumion batteries. The selection was based on technological maturity, costs and technical parameters. Studies on grid-level energy storage technologies consider several electrochemical options [4, 11, 14, 34-37], but the scope of this work is not a broad evaluation of all storage options, therefore narrowing down the choice to the three most promising is a good compromise.

Storage capacity is calculated endogenously, meaning that the model calculates the optimal storage capacity required for a given scenario. Just like power plants, storage units are not defined by location, meaning that electricity can be stored and released as long as the capacity is available. All three technologies are simultaneously valid as options, allowing a mix of technologies as a theoretical optimal result, for example. The choice between the technologies is decided based on their annualized life cycle costs (ALCC) and technical parameters (Table 4): self-discharge, roundtrip efficiency and energy-to-power ratio.

The costs of the technologies are represented not simply by their capital costs, but by the annualized life cycle costs. As argued by [36], ALCC is one of the more important indicators to evaluate and compare different electrical energy storage systems, since it takes into account expenses

Table 4 Technical parameters of the selected electrochemical technologies

\begin{tabular}{lllll}
\hline & $\begin{array}{l}\text { Lithium- } \\
\text { ion }\end{array}$ & VRFB & NaS & PHS \\
\hline Self-discharge (daily) & $0.20 \%$ & 0 & $5 \%$ & 0 \\
Roundtrip efficiency & $95 \%$ & $80 \%$ & $85 \%$ & $70 \%$ \\
Energy-to-power ratio & 2 & 3 & 7 & 6 \\
$\begin{array}{l}\text { Annualized life cycle costs (ALCC), } \\
€ / \text { kW-yr }\end{array}$ & 271.8 & 297.7 & 297.7 & - \\
\hline
\end{tabular}

related to fixed operation and maintenance, variable operation and maintenance, replacement, disposal and recycling, as well as total capital costs. The parameters used to calculate the ALCC for all technologies are found in [36]. The final ALCC is presented in Table 4.

\section{Mathematical formulation of the model}

The optimization in the model is achieved through the maximization of the grid "revenue", given by the export/ import balance, the commissioning of storage units and natural gas costs (Eq. 1).

$$
\begin{aligned}
& \text { max gridRevenue }=\sum_{t} \text { exportElec }_{t}
\end{aligned}
$$

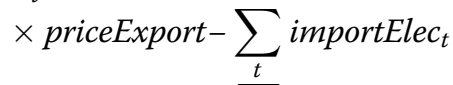

$$
\begin{aligned}
& \times \text { priceImport }-\sum_{s}^{t} \text { CostPerkWyr } \\
& \times \text { enpoRatio }_{\text {s }} \\
& \times \text { storageCapacity }_{s}-\sum_{t} \text { gas }_{t} \\
& \times \text { priceGas }
\end{aligned}
$$

Demand has to be satisfied through electricity provided by any of the sources in the model, be it renewable energy, baseload, dispatchable, stored energy or imports.

$$
\begin{aligned}
\text { renewableEnerg }_{t} & + \text { baseloadEnergy }_{t}+\text { pumpedHydro }_{t} \\
& + \text { gast }_{t}+\text { importElec }_{t}+\sum_{\text {storeOut }_{t, s}-\text { exportElec }_{t}} \text { store }_{t, s} \text { demand }_{t} \geq 0, \quad \forall t
\end{aligned}
$$

Equation 3 describes the electricity inflow and outflow at each time step, for each storage technology, taking into account self-discharge and roundtrip efficiency. Equation 4 defines the upper bound of the total energy stored at any given time.

$$
\begin{aligned}
\text { storageCurrent }_{t, s} & =\text { storageCurrent }_{t-1, s} *\left(1-\text { selfDischarge }_{s}\right) \\
& + \text { storeIn }_{t, s} * \text { roundTripEff }_{s}-\text { storeOut }_{t, s}, \quad \forall t, \forall s
\end{aligned}
$$

$$
\text { storageCurrent }_{t, s} \leq \text { storageCapacity }_{s}, \quad \forall t, \forall s
$$

From here on, some constraints will be marked with a conditional statement, whether they apply in a surplus or deficit condition. These conditions are defined by evaluating the available generation from renewables, baseload and must-run at any given time $t$ (Eqs. 5 and 6).

Surplus condition: 
$\mathrm{t}$ in which renewableEnergy $y_{t}+$ baseloadEnergy $_{t}$

$$
+ \text { gas }_{\text {min }} \geq \text { demand }_{t}
$$

Deficit condition:

$$
\begin{aligned}
& \mathrm{t} \text { in which renewableEnergy } \\
& \quad+\text { gas }_{\min } \leq \text { demand }_{t} .
\end{aligned}
$$

Equations 7 and 8 prevent electricity being stored in a deficit condition (not enough generation to satisfy demand) and electricity being released under a surplus condition (available electricity exceeds demand).

$$
\operatorname{storeIn}_{t, s}=0, \quad \forall t, \forall s ;(\text { if deficit condition is true })
$$

storeOut $_{t, s}=0, \quad \forall t, \forall s ;($ if surplus condition is true $)$

The amount of electricity that can be stored in a storage unit at any given time depends on the surplus at that time. An equivalent statement can be made regarding the electricity released from the storage unit to the grid, which cannot be more than the grid needs. These constraints are described by Inequalities 9 and 10 .

$$
\begin{aligned}
\sum_{s} \text { storeI }_{t, s} \leq \text { renewableEnergy }_{t}+\text { baseloadEnergy }_{t}+\text { gas }_{\text {min }} \\
\\
+ \text { importElec }_{t}-\text { exportElec }_{t}-\text { demand }_{t}, \quad \forall t
\end{aligned}
$$$$
\text { (if surplus condition is true) }
$$

$$
\begin{aligned}
& \sum_{s} \text { storeOut }_{t, s} \\
& \leq \text { demand }_{t}+\text { exportElec }_{t}-\text { renewableEnergy }_{t} \\
&- \text { baseloadEnergy }_{t}-\text {-gas }_{\text {min }}-\text { importElec }_{t}, \quad \forall t \\
& \quad(\text { if deficit condition is true })
\end{aligned}
$$

Constraint 11 limits the amount of electricity being released from the storage unit to the grid to the total amount currently stored. Constraint 12 limits the total electricity flow for a given time step.

$$
\begin{gathered}
\text { storeOut }_{t, s} \leq \text { storageCurrent }_{t-1, s}, \quad \forall t, \forall s \\
\text { (if deficit condition is true) }
\end{gathered}
$$

$$
\begin{aligned}
& \text { storeIn }_{t, s} \\
& \quad+\text { storeOut }_{t, s} \leq \frac{\text { storageCapacity }_{s}}{\text { enpoRatio }_{s}}, \quad \forall t, \forall s
\end{aligned}
$$

Dispatchable generation is described by Constraints 13 to 17. Constraint 13 applies when there is not enough electricity supply to satisfy the demand. Constraints 14 and 15 set the lower and upper bounds for the dispatch of natural gas and pumped hydro. Finally, Eqs. 16 and
17 set the behavior of dispatch generation when there is surplus of electricity.

$$
\begin{aligned}
& \text { pumpedHydro }_{t}+\text { gas }_{t}+\text { importElec }_{t} \\
& \quad=\text { demand }_{t}-\text { baseloadEnergy }_{t}-\text { renewableEnergy }_{t}, \quad \forall t \\
& \text { (if deficit condition is true) }
\end{aligned}
$$

$$
\begin{aligned}
& \text { pumpedHydro }_{t} \leq \text { pumpedHydro }_{\text {peak }}, \quad \forall t \\
& \text { gas }_{\text {min }} \leq \text { gas }_{t} \leq \text { gas }_{\text {peak }}, \quad \forall t \\
& \text { gas }_{t}=\text { gas }_{\text {min }}, \quad \forall t \quad \text { (if surplus condition is true) }
\end{aligned}
$$

$$
\text { pumpedHydro }{ }_{t}=0, \quad \forall t \text { (if surplus condition is true) }
$$

Four constraints dictate the boundaries for imports and exports. Two types of boundaries are set here: one hourly limit for imported or exported electricity (Ineqs. 19 and 21), based on real data, and a limit to the total amount of electricity traded within the model time horizon of one year (Ineqs. 18 and 20). Eqs. 22 and 23 prevent imports during surplus and exports during deficit.

$$
\sum_{t} \text { importElec }_{t} \leq \text { maxImport }
$$

importElec $_{t} \leq$ maxImportHour,$\quad \forall t$

$\sum_{t}$ exportElec $_{t} \leq \max$ Export

exportElec $_{t} \leq$ maxExportHour,$\quad \forall t$

importElec $_{t}=0$ (if surplus condition is true)

exportElec $_{t}=0$ (if deficit condition is true)

\section{Scenarios}

The scenarios that are evaluated are taken from the NEP reports [31], where projections for 2025 and 2035 are made based on a series of assumptions, such as fuel prices, decommissioning of conventional power plants, commissioning of renewable energy plants and imports/exports. Table 5 shows the parameters used in the projections for the proposed scenarios.

In this work, two "corridors" from 2016/17 are pictured (Fig. 8), each containing 3 landmarks: 2025, 2035 and 2050. Corridor A is characterized by a business-as-usual outcome, where the market does not respond to renewable energy/decarbonisation policies swiftly enough, phase-out of conventional sources happen at a slower pace and 2050 goals for the energy transition are not reached. Corridor B depicts a more optimistic prospect, where 2050 goals are 
Table 5 Parameters used in the scenario projections

\begin{tabular}{|c|c|c|c|c|c|c|c|}
\hline & 2017 & $2025 \mathrm{~A}$ & $2025 B$ & $2035 \mathrm{~A}$ & $2035 B$ & $2050 \mathrm{~A}$ & $2050 \mathrm{~B}$ \\
\hline $\begin{array}{l}\text { Demand (gross, } \\
\text { TWh) }\end{array}$ & 596 & 580 & 600 & 570 & 615 & 560 & 630 \\
\hline $\begin{array}{l}\text { Natural gas must- } \\
\text { run (GW) }\end{array}$ & 1.3 & 1.3 & 1.5 & 1.4 & 1.8 & 2.1 & 1.8 \\
\hline $\begin{array}{l}\text { Natural gas peak } \\
\text { prod. (GW) }\end{array}$ & 17.0 & 17.0 & 19.6 & 18.4 & 23.5 & 27.5 & 22.9 \\
\hline $\begin{array}{l}\text { Pumped hydro } \\
\text { peak prod. (GW) }\end{array}$ & 6.0 & 9.0 & 9.0 & 9.0 & 12.8 & 9.6 & 12.9 \\
\hline $\begin{array}{l}\text { Total imports } \\
\text { (GWh) }\end{array}$ & $\begin{array}{l}26 \\
000\end{array}$ & $\begin{array}{l}53 \\
000\end{array}$ & $\begin{array}{l}42 \\
300\end{array}$ & $\begin{array}{l}96 \\
100\end{array}$ & $\begin{array}{l}66 \\
300\end{array}$ & $\begin{array}{l}96 \\
100\end{array}$ & $\begin{array}{l}80 \\
000\end{array}$ \\
\hline $\begin{array}{l}\text { Total exports } \\
\text { (GWh) }\end{array}$ & $\begin{array}{l}77 \\
000\end{array}$ & $\begin{array}{l}124 \\
200\end{array}$ & $\begin{array}{l}135 \\
700\end{array}$ & $\begin{array}{l}104 \\
000\end{array}$ & $\begin{array}{l}143 \\
700\end{array}$ & $\begin{array}{l}104 \\
000\end{array}$ & $\begin{array}{l}150 \\
000\end{array}$ \\
\hline $\begin{array}{l}\text { Import avg. price } \\
(€ / G W h)\end{array}$ & $\begin{array}{l}35 \\
600\end{array}$ & $\begin{array}{l}35 \\
600\end{array}$ & $\begin{array}{l}35 \\
600\end{array}$ & $\begin{array}{l}35 \\
600\end{array}$ & $\begin{array}{l}35 \\
600\end{array}$ & $\begin{array}{l}35 \\
600\end{array}$ & $\begin{array}{l}35 \\
600\end{array}$ \\
\hline $\begin{array}{l}\text { Export avg. price } \\
(€ / G W h)\end{array}$ & $\begin{array}{l}32 \\
330\end{array}$ & $\begin{array}{l}32 \\
330\end{array}$ & $\begin{array}{l}32 \\
330\end{array}$ & $\begin{array}{l}32 \\
330\end{array}$ & $\begin{array}{l}32 \\
330\end{array}$ & $\begin{array}{l}32 \\
330\end{array}$ & $\begin{array}{l}32 \\
330\end{array}$ \\
\hline $\begin{array}{l}\text { Price natural gas } \\
\text { (cent } € / k W h \text { ) }\end{array}$ & 3.00 & 3.19 & 3.19 & 3.37 & 3.37 & 3.5 & 3.5 \\
\hline
\end{tabular}

reached and/or surpassed and conventional phase-out takes place at a faster rate. Projected installed capacities for every power source in the model and GHG emissions reduction for each scenario are presented in Table 6. Emissions were calculated by taking into account brown coal, hard coal and natural gas emissions. Reduction percentages are calculated based on 1990 emissions, since the reduction targets for the Energy Transition are calculated with 1990 as the starting point. These values only pertain to the energy sector. Full-load hours of aggregated baseload generation are shown in Table 7.
Table 6 Projected installed capacity and GHG emissions reduction

\begin{tabular}{llllllll}
\hline & $2017[1]$ & $2025 \mathrm{~A}$ & $2025 \mathrm{~B}$ & $2035 \mathrm{~A}$ & $2035 \mathrm{~B}$ & $2050 \mathrm{~A}$ & $2050 \mathrm{~B}$ \\
\hline Wind (onshore) & 50.9 & 53.0 & 63.8 & 60.0 & 88.8 & 62.0 & 95.0 \\
Wind (offshore) & 5.3 & 8.9 & 10.5 & 9.0 & 18.5 & 15.0 & 37.0 \\
$\mathrm{PV}$ & 42.8 & 54.0 & 55.0 & 58.0 & 60.0 & 70.0 & 100.0 \\
Nuclear & 10.8 & 0 & 0 & 0 & 0 & 0 & 0 \\
Coal (Hard) & 25.0 & 26.0 & 22.0 & 21.0 & 11.0 & 10.0 & 0 \\
Coal (Lignite) & 21.3 & 14.0 & 13.0 & 12.0 & 9.0 & 5.0 & 0 \\
Natural gas & 29.5 & 29.5 & 34.0 & 37.0 & 41.0 & 48.0 & 40.0 \\
Hydro & 5.6 & 8.5 & 8.5 & 8.5 & 12.0 & 9.0 & 12.0 \\
Biomass & 7.4 & 7.5 & 8.5 & 7.5 & 9.5 & 8.0 & 15.0 \\
PHS (storage) & 6.8 & 7.1 & 7.5 & 7.5 & 8.3 & 7.8 & 9.3 \\
$\begin{array}{l}\text { Emissions } \\
\text { (energy sector }\end{array}$ & 333 & 264.5 & 247.9 & 241.2 & 183.6 & 160.8 & 67.6 \\
only, million & & & & & & & \\
tonnes CO ${ }^{2}$-eq) & & & & & & & \\
$\begin{array}{l}\text { Emission } \\
\text { reduction (rel. }\end{array}$ & 22 & 38 & 42 & 44 & 57 & 62 & 84 \\
to 1990, \%) & & & & & & & \\
\hline
\end{tabular}

The total gross electricity demand projections in Table 5 are made based mainly on the "sector coupling" that is expected to occur in the coming decades. Regarding the transport sector, the electric vehicle (EV) fleet is expected to reach 1 to 6 million cars by 2030. The impact of EVs is computed as an increase in electricity demand based on the average capacity of the batteries and the type of EV [15]. Vehicle-to-grid technology [38], where battery in EVs are used for ancillary services, are not considered in this work. The integration with the heat sector is consolidated
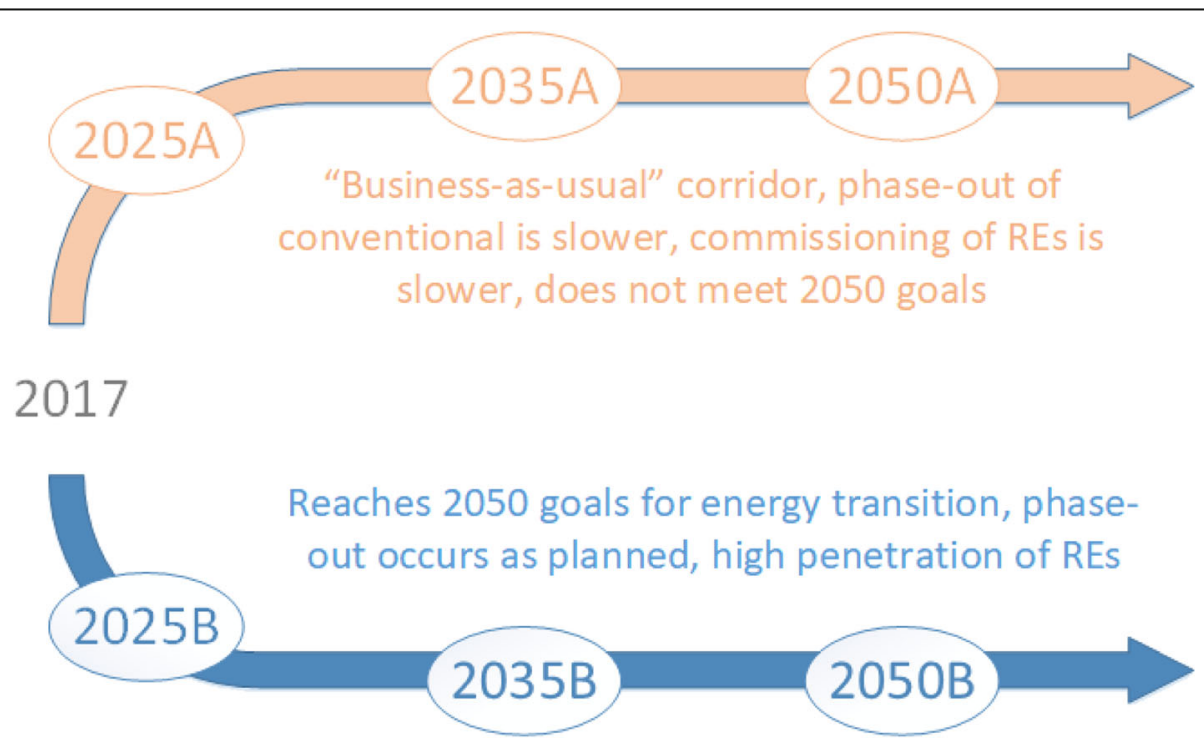

Fig. 8 Two corridors from 2016 are proposed: Corridor A represents a "business as usual" projection, while Corridor B represents a more optimistic projection 
Table 7 Full-load hours of baseloadGeneration

\begin{tabular}{lll}
\hline Scenario & Total energy generated (year, TWh) & Full-load hours \\
\hline $2025 A$ & 279 & 5070 \\
$2025 B$ & 257 & 4942 \\
$2035 A$ & 243 & 4860 \\
$2035 B$ & 193 & 5514 \\
$2050 A$ & 153 & 5100 \\
$2050 B$ & 122 & 6100 \\
\hline
\end{tabular}

through heat pumps, where the number of heat pump systems is expected to grow 2 to 7 times [39]. Improvements in transmission losses and energy efficiency are also expected to take place, slightly reducing gross electricity demand. The net effect (increase or decrease) is dependent on how fast sector coupling happens. In Corridor $\mathrm{A}$, we assume that EV fleet and heat pump integration have a slower adoption than in Corridor $B$, therefore resulting in the gross electricity demand projections.

Residual load duration curves of all scenarios are shown in Fig. 9. The residual load is calculated by subtracting variable renewable energy generation from the load, hence it can be defined as the load that has to be satisfied by other types of generation, such as natural gas, coal or hydro. The hourly values for the entire year are then sorted in decreasing order and plotted. This allows visualizing how high are the peaks, what the surplus hours are, and how often they happen throughout the year. As renewable energy takes bigger chunks of the energy mix, positive residual load tends to decrease, while negative residual load increases. In other words, this means an increase in accumulated hours of yearly surplus and less reliance on must-run conventional power plants.

The role of grid-level storage systems can also be analyzed through the perspective of residual load. Surplus of electricity will be more common in the coming decades, which poses the question: what can be done with the excess electricity? Options are: a) to be exported. This is a versatile option even in today's grid, but it does not guarantee to solve the problem, as neighboring countries might also be experiencing surplus in their respective networks during the same period. Another option is b) curtailing; thoroughly explored and discussed in Olson et al. [24]. Energy curtailment is a low-cost power system flexibility tool, requiring no significant up-front investment, but with the potential downside of contractual and regulatory issues. A third option is to prevent, or at least reduce, the surplus in the first place, with c) demand-side management (DSM) measures, which attempts at reducing or shifting the load from customers through financial incentives or behavioral changes. Finally, surplus electricity can be d) stored into grid-connected storage system units to be used in subsequent periods of low generation. By deriving residual load duration curves, a quick look at the surplus accumulated hours (negative residual load) already foreshadows the need for the system flexibility options that are discussed in our work. All of the aforementioned solutions for surplus electricity are included in the model, except DSM.

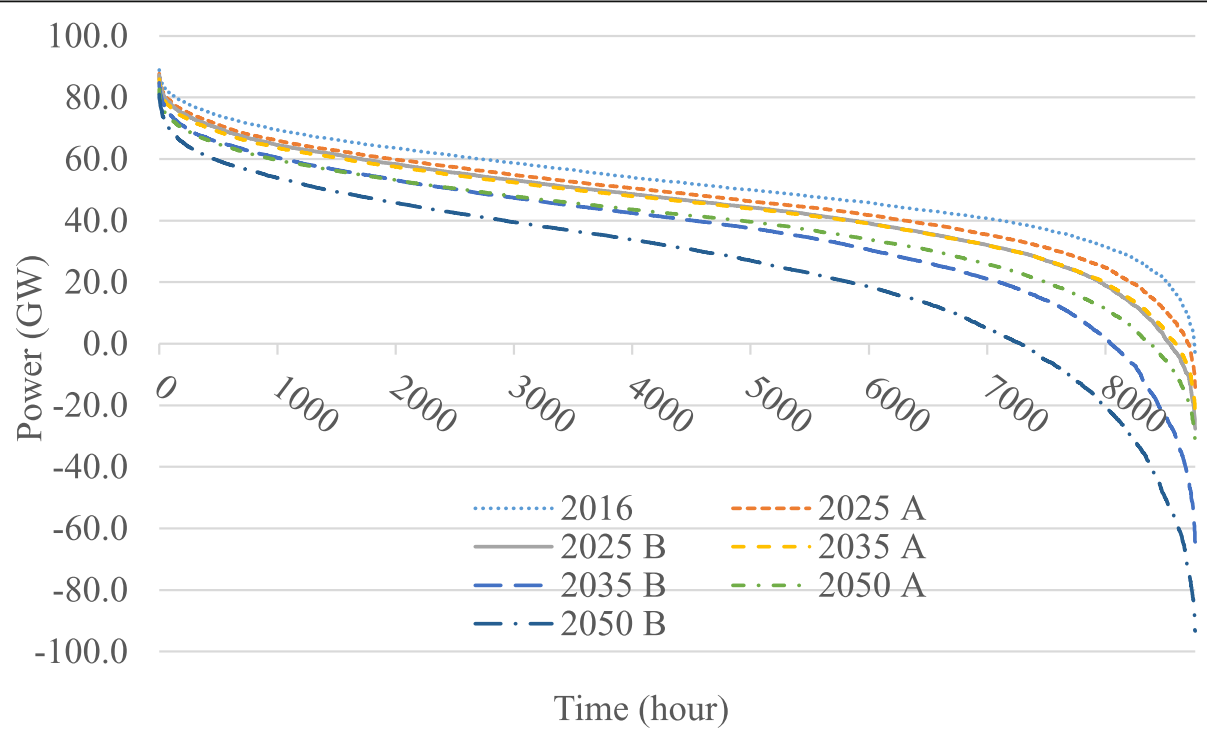

Fig. 9 Residual load curves across all scenarios. (COLOR IN PRINT) 


\section{Abbreviations}

ALCC: Annualized life cycle costs; DSM: Demand-side management; ES: Energy storage; EV: Electric vehicle; LP: Linear programming; NaS: Sodium-sulphur battery; P2G: Power-to-gas; PHS: Pumped-hydro storage; PV: Photovoltaic; s: Storage technology; SNG: Synthetic natural gas; $t$ : Time (hours); VRE: Variable renewable energy; VRFB: Vanadium redox flow battery

\section{Acknowledgements}

Not applicable.

\section{Authors' contributions}

Authors L.K.K.M and E.Z. have made substantial contributions to the conception of this work, to the interpretation of the data, to the writing and revision of this work

Authors L.K.K.M and E.Z. have approved the submitted version. Authors L.K.K.M and E.Z. have agreed both to be personally accountable for their own contributions and to ensure that questions related to the accuracy or integrity of any part of the work, even ones in which the author was not personally involved, are appropriately investigated, resolved, and the resolution documented in the literature.

\section{Funding}

This research did not receive any specific grant from funding agencies in the public, commercial, or not-for-profit sectors.

\section{Availability of data and materials}

Electricity demand data used in this article can be found at the ENTSO-E website [27]. Power generation data can be found in the Fraunhofer ISE Energy Charts [1]. Projections for the power capacities in the studied scenarios were based on the NEP reports [39].

\section{Competing interests}

The author(s) declare(s) that they have no competing interests.

Received: 22 April 2019 Accepted: 22 October 2019

Published online: 04 December 2019

\section{References}

1. F. ISE, Energy charts, (2018). https://www.energy-charts.de. (Accessed 9 Mar 2018).

2. BMWi, A good Piece of Work The Energy of the Future, Fourth "The Energy Transition" Monitoring Report-Summary, (2015) 26. https://www. bmwi.de/BMWi/Redaktion/PDF/N/vierter-monitoring-bericht-energie-derzukunft-englische-kurzfassung, property=pdf,bereich=bmwi2012,sprache= de,rwb=true.pdf.

3. Ueckerdt F, Brecha R, Luderer G. Analyzing major challenges of wind and solar variability in power systems. Renew Energy. 2015;81:1-10. https://doi. org/10.1016/j.renene.2015.03.002.

4. Gallo AB, Simões-Moreira JR, Costa HKM, Santos MM, Moutinho dos Santos E. Energy storage in the energy transition context: a technology review. Renew Sust Energ Rev. 2016;65:800-22. https://doi.org/10.1016/j. rser.2016.07.028

5. Gimeno-Gutiérrez M, Lacal-Arántegui R. Assessment of the European potential for pumped hydropower energy storage based on two existing reservoirs. Renew Energy. 2015;75:856-68. https://doi.org/10.1016/j.renene. 2014.10.068

6. Buttler A, Spliethoff $\mathrm{H}$. Current status of water electrolysis for energy storage, grid balancing and sector coupling via power-to-gas and power-toliquids: a review. Renew Sust Energ Rev. 2018:82:2440-54. https://doi.org/10. 1016/j.rser.2017.09.003

7. Pleßmann G, Erdmann M, Hlusiak M, Breyer C. Global energy storage demand for a 100\% renewable electricity supply. Energy Procedia. 2014;46: 22-31. https://doi.org/10.1016/j.egypro.2014.01.154.

8. Palizban O, Kauhaniemi K. Energy storage systems in modern grids???Matrix of technologies and applications. Adv Life Course Res. 2016;6:248-59. https://doi.org/10.1016/j.est.2016.02.001.

9. Schlachtberger DP, Brown T, Schramm S, Greiner M. The benefits of cooperation in a highly renewable European electricity network. Energy. 2017;134:469-81. https://doi.org/10.1016/j.energy.2017.06.004
10. Brivio C, Mandelli S, Merlo M. Battery energy storage system for primary control reserve and energy arbitrage, sustain. Energy, grids. Networks. 2016; 6:152-65. https://doi.org/10.1016/j.segan.2016.03.004

11. Jülch V. Comparison of electricity storage options using levelized cost of storage (LCOS) method. Appl Energy. 2016;183:1594-606. https://doi.org/10. 1016/j.apenergy.2016.08.165.

12. Slocum AH, Fennell GE, Dündar G, Hodder BG, Meredith JDC, Sager MA. Ocean renewable energy storage (ORES) system: analysis of an undersea energy storage concept. Proc IEEE. 2013;101:906-24. https://doi.org/10.1109/ JPROC.2013.2242411.

13. International Hydropower Association, Hydropower Status Report, (2017) 183.

14. C. Pape, N. Gerhardt, P. Härtel, A. Scholz, R. Schwinn, T. Drees, A. Maaz, J. Sprey, C. Breuer, A. Moser, F. Sailer, S. Reuter, T. Müller, Roadmap Speicher Speicherbedarf für Erneuerbare Energien - Speicheralternativen Speicheranreiz - Überwindung Rechtlicher Hemmnisse, (2014) 126.

15. Trost T, Sterner M, Bruckner T. Impact of electric vehicles and synthetic gaseous fuels on final energy consumption and carbon dioxide emissions in Germany based on long-term vehicle fleet modelling. Energy. 2017;141: 1215-25. https://doi.org/10.1016/j.energy.2017.10.006.

16. Science Direct, Elsevier. (n.d.). www.sciencedirect.com. (Accessed 13 Mar 2018).

17. Cebulla F, Naegler T, Pohl M. Electrical energy storage in highly renewable European energy systems: capacity requirements, spatial distribution, and storage dispatch. J Energy Storage. 2017;14:211-23. https://doi.org/10.1016/j. est.2017.10.004.

18. Pleßmann G, Blechinger P. How to meet EU GHG emission reduction targets? A model based decarbonization pathway for Europe's electricity supply system until 2050. Energy Strateg Rev. 2017;15:19-32. https://doi.org/ 10.1016/j.esr.2016.11.003.

19. Pfenninger S, Hawkes A, Keirstead J. Energy systems modeling for twentyfirst century energy challenges. Renew Sust Energ Rev. 2014;33:74-86. https://doi.org/10.1016/j.rser.2014.02.003.

20. Schill WP, Zerrahn A. Long-run power storage requirements for high shares of renewables: results and sensitivities. Renew Sust Energ Rev. 2017:1-16. https://doi.org/10.1016/j.rser.2017.05.205.

21. Lunz B, Stöcker P, Eckstein S, Nebel A, Samadi S, Erlach B, Fischedick M, Elsner P, Sauer DU. Scenario-based comparative assessment of potential future electricity systems - a new methodological approach using Germany in 2050 as an example. Appl Energy. 2016;171:555-80. https://doi.org/10. 1016/j.apenergy.2016.03.087.

22. Babrowski $\mathrm{S}$, Jochem $\mathrm{P}$, Fichtner $\mathrm{W}$. Electricity storage systems in the future German energy sector: an optimization of the German electricity generation system until 2040 considering grid restrictions. Comput Oper Res. 2016;66: 228-40. https://doi.org/10.1016/j.cor.2015.01.014

23. Gils HC, Scholz Y, Pregger T, Luca de Tena D, Heide D. Integrated modelling of variable renewable energy-based power supply in Europe. Energy. 2017; 123:173-88. https://doi.org/10.1016/j.energy.2017.01.115.

24. Olson A, Jones RA, Hart E, Hargreaves J. Renewable curtailment as a power system flexibility resource. Electr J. 2014;27:49-61. https://doi.org/10.1016/j. tej.2014.10.005.

25. Götz M, Lefebvre J, Mörs F, McDaniel Koch A, Graf F, Bajohr S, Reimert R, Kolb T. Renewable power-to-gas: a technological and economic review. Renew Energy. 2016;85:1371-90. https://doi.org/10.1016/j.renene.2015.07.066.

26. Maia LKK, Drünert L, La Mantia F, Zondervan E. Expanding the lifetime of liion batteries through optimization of charging profiles. J Clean Prod. 2019; 225:928-38. https://doi.org/10.1016/j.jclepro.2019.04.031.

27. ENTSO-E - European Network of Transmission System Operators for Electricity, (n.d.). https://www.entsoe.eu.

28. Netztransparenz.de, (n.d.). https://www.netztransparenz.de/.

29. AIMMS, (n.d.). https://www.aimms.com. (Accessed 7 July 2019).

30. ENTSO-E, (n.d). www.entsoe.eu. (Accessed 20 Nov 2017).

31. NEP, Netzentwicklungsplan Strom 2025, (2015).

32. Jentsch M, Trost T, Sterner M. Optimal use of power-to-gas energy storage systems in an 85\% renewable energy scenario. Energy Procedia. 2014;46: 254-61. https://doi.org/10.1016/j.egypro.2014.01.180.

33. Pregger $T$, Nitsch J, Naegler T. Long-term scenarios and strategies for the deployment of renewable energies in Germany. Energy Policy. 2013;59:350 60. https://doi.org/10.1016/j.enpol.2013.03.049.

34. G. Fuchs, B. Lunz, M. Leuthold, D.U. Sauer, Technology Overview on Electricity Storage, Inst. Power Electron. Electr. Drives (ISEA), RWTH Aachen 
Univ. (2012) 66. http://www.sefep.eu/activities/projects-studies/120628_ Technology_Overview_Electricity_Storage_SEFEP_ISEA.pdf.

35. Budischak C, Sewell D, Thomson H, MacH L, Veron DE, Kempton W. Costminimized combinations of wind power, solar power and electrochemical storage, powering the grid up to $99.9 \%$ of the time. J. Power Sources. 2013; 225:60-74. https://doi.org/10.1016/j.jpowsour.2012.09.054.

36. Zakeri B, Syri S. Electrical energy storage systems: a comparative life cycle cost analysis. Renew Sust Energ Rev. 2015;42:569-96. https://doi.org/10. 1016/j.rser.2014.10.011

37. Obi M, Jensen SM, Ferris JB, Bass RB. Calculation of levelized costs of electricity for various electrical energy storage systems. Renew Sust Energ Rev. 2017;67:908-20. https://doi.org/10.1016/..rser.2016.09.043.

38. Habib S, Kamran M, Rashid U. Impact analysis of vehicle-to-grid technology and charging strategies of electric vehicles on distribution networks - a review. J Power Sources. 2015;277:205-14. https://doi.org/10.1016/j. jpowsour.2014.12.020.

39. NEP, Netzentwicklungsplan Strom 2030, version 2017. www. netzentwicklungsplan.de. (Accessed Nov 2017).

\section{Publisher's Note}

Springer Nature remains neutral with regard to jurisdictional claims in published maps and institutional affiliations.

Ready to submit your research? Choose BMC and benefit from:

- fast, convenient online submission

- thorough peer review by experienced researchers in your field

- rapid publication on acceptance

- support for research data, including large and complex data types

- gold Open Access which fosters wider collaboration and increased citations

- maximum visibility for your research: over $100 \mathrm{M}$ website views per year

At BMC, research is always in progress.

Learn more biomedcentral.com/submissions 